\title{
Critical Success Factors That Influence Black Leadership Integration in Companies Listed on the Johannesburg Securities Exchange
}

\author{
Biren Valodia ${ }^{1}$, Ted Sun ${ }^{1} \&$ Thomas Zachariah $^{1}$ \\ ${ }^{1}$ SMC University, South Africa \\ ${ }^{2}$ Transcontinental Institution of Higher Education, South Africa \\ Correspondence: Biren Valodia, SMC University, South Africa. E-mail: valodia@mweb.co.za
}

Received: February 12, 2018

Accepted: March 12, 2018

Online Published: April 18, 2018

doi:10.5539/ijbm.v13n5p72

URL: https://doi.org/10.5539/ijbm.v13n5p72

\begin{abstract}
In the context of post-apartheid period, there have been certain measures introduced to have employment equity in South Africa. The integration of black leadership in a white dominant companies was one among them. The purpose of this study is to identify the critical success factors that influence black leadership integration as per the reform measures defined after post-apartheid period in South Africa. The overall research question guiding this study is: What are the critical success factors that influence black leadership integration in companies listed on the Johannesburg Securities Exchange? The quantitative correlation research design utilizes a pre-validated survey to access the success factors that influence black leadership integration. To address the research question, the independent variables - corporate culture, leadership style, diversity and strategic leadership behaviours were correlated with three dependent variables - tenure (years of service), job satisfaction and growth satisfaction (career development opportunities) as measures of successful leadership integration. The study finds statistically significant relationships amongst many of the 32 constructs identified in the literature which using factor analysis are described as fair treatment, job hopping, commitment to transformation, Black entrepreneurship and corporate culture. As defined by Black management, job satisfaction, career development (dependent variables), fair treatment and specific leaders behaviours (inspirational motivation and idealised attributes) (independent variables) as defined by MLQ 5X leadership survey are critical success measures that could influence Black leadership integration in Johannesburg Securities Exchange (JSE) listed companies. The results of this study provide strong evidence of critical success factors that have a statistically significant influence on successful Black leadership integration into historically White dominated South African companies.
\end{abstract}

Keywords: black leadership, white management, South Africa

\section{Introduction}

In 1994, apartheid (racial segregation) was abolished in South Africa, resulting in the advent of a constitutional democracy. There were various law reform efforts that have been initiated to achieve greater social equality and justice (Horwitz, Jain \& Mbabane, 2005). To redress past unfair discrimination, the Labour Relations Act of 1995, the Constitution of Africa, 1996 and the Basic Conditions of Employment Act of 1997 were mandated. Furthermore, the Employment Equity Act of 1999 (amended in 2004) which incorporate anti-discriminatory provisions was put into effect, along with the Skills Development Act of 1998 and the Skills Development Levies Act of 1999. The last two acts focussed on the succession, planning, training, development and recruitment of discriminated groups (Africans, Coloureds, Indians and women and people with disabilities) and also accentuated on the skills gap (Horwitz et al., 2005; Rautenbach, 2005). Following these acts was the establishment of the Broad-Based Black Economic Empowerment (BBBEE) Commission in 1999, and various other strategies devised by the Government and industry to further the black representation in business and management (Booysen, 2007). However, in 2013, despite various legislative interventions, most top and senior management positions in South African companies are still held by white individuals (Employment Equity Report, 2011).

Attracting and retaining black professionals has become an urgent priority for many companies to ensure compliance with legislation and to embrace the country's transformation agenda. Failure by companies to comply could lead to codes becoming more legally enforceable and punitive. Despite the importance catered to the codes and potential punitive action behind the absence of it hasn't substantially improved the condition of the 
black population. According to Tangri \& Southall (2008), the impacted black individuals, who are unable to reap the benefits of the mandates devised, can become disgruntled, potentially leading to social disobedience and unrest if empowerment is not implemented faster. Failure by organisations to achieve employment equity targets and Broad-Based Black Economic Empowerment Act (BBBEE) contribution level scores will result in the potential exclusion from participating in state-based tender processes and from being acknowledged as preferred procurement companies.

Legislative frameworks were introduced to support the appointment of previously disadvantaged black individuals in senior positions (Act B.B.B.E.E., 2004). In 2010, black people accounted for approximately $86 \%$ of all employees with only $16.9 \%$ represented at top management level and $35.9 \%$ at senior management level (Employment Equity Report, 2011). A comprehensive analysis of qualified professionals (black and white) between 2006 and 2010 shows a gradual increase in the number of black professionals employed. In 2010, black professionals accounted for approximately 50\% (31\% African, 10.4\% Coloured, and 8.8\% Indians). However, the integration of black professionals into these positions has been extremely slow (Employment Equity Report, 2011).

The various conducted researches provided various explanations to ascertain the failure of the companies to attract or retain upper-level black managers (Nzukuma \& Bussin, 2011; Vass, 2010). However, the literature failed to identify critical success factors from both individual and company perspectives that drive the attraction and retention of top black leaders. Thus, this study would exclusively focus on providing an insight regarding the critical success factors, and fills the apparent gap in the literature.

\subsection{Purpose and Objectives}

The purpose of this study is to identify critical success factors that impact successful black leadership integration into white dominated companies. With the participation of top and senior managers (black and white) from 198 JSE-listed companies, the researcher aims to investigate the critical success factors - or independent variables that influence the successful integration of new black leaders.

\subsection{Research Question}

The objective of this study is to identify the key critical success factors that will influence successful Black leadership integration into Johannesburg Securities Exchange (JSE) listed companies in South Africa. The research questions consist of 1 overall primary question and 12 sub-questions answering the overall question.

What are the critical success factors that influence black leadership integration in companies listed on the Johannesburg Securities Exchange?

This overall question is broken down into 4 sub questions. The research questions are:

1) $\mathbf{R}_{\mathbf{1}}$ : Is there a statistical correlation between critical success factors influencing leadership integration and tenure in the previous job?

2) $\quad \mathbf{R}_{\mathbf{2}}$ : Is there a statistical correlation between critical success factors influencing leadership integration and tenure in the current job?

3) $\quad \mathbf{R}_{\mathbf{3}}$ : Is there a statistical correlation between critical success factors influencing leadership integration and job satisfaction?

4) $\quad \mathbf{R}_{\mathbf{4}}$ : Is there a statistical correlation between critical success factors influencing leadership integration and career development?

In accordance with the respective research questions, the following hypothesis and null hypotheses were generated:

- H1: A statistical correlation between critical success factors influencing leadership integration and tenure in the previous job exists.

- H2: A statistical correlation between critical success factors influencing leadership integration and tenure in the current job exists.

- H3: A statistical correlation between critical success factors influencing leadership integration and job satisfaction exists.

- H4: A statistical correlation between critical success factors influencing leadership integration and career development exists. 


\subsection{Significance of the Study}

This study will identify those critical success factors that influence black leadership integration by providing an understanding of the factors that drive the recruitment and retention of black management (Employment Equity Report, 2011). Thus, such identification might assist JSE-listed and other companies to achieve their empowerment targets.

The next section reviews literature on the legislative, cultural, international and other contexts in which black leaders in South Africa operate.

\section{Literature Review}

The literature review explored the theoretical and empirical basis of this study, and the conclusions reached by other researchers who have investigated similar constructs, research questions and variables. The motive of the literature review is to highlight the lack of black representation in organisation despite the prevalence of extensive legal framework that aims to eradicate such inequality. This review will substantiate the research conducted by the author and will aid to assess the critical success factors that would augment the integration of black leadership in the companies.

\subsection{The South African Context}

BBBEE is a process aimed at altering the South African economy by the expanse of equity holdings to involve previously disadvantaged South Africans, ensuring greater participation to attain economic justice and to re-organise the management structure (Osode, 2004). The BBBEE regulatory framework is based on the Constitution provision 9(2) that focuses on the right to equality and mandates legal guidelines that aims to redress historical inequalities. In the case of employment equity, the designated groups in the legislation are defined as 'black people' that includes of Africans, Coloured, Indians and Chinese South Africans. Other designated groups include women and people with disabilities. Codes of good practice have been issued by the Department of Trade and Industries and were gazetted in February 2007 (Horwitz \& Jain, 2011). At the time of the study, the code was inclusive of seven sub-elements of BBBEE, which are grouped into three categories, namely, direct empowerment - ownership and managerial control; human resource development - employment equity and skills development; and indirect empowerment - preferential procurement, enterprise development and socioeconomic development and sector specific contributions (Department of Trade and Industry, 2004). Today, the code is inclusive of five sub-elements of BBBEE, ownership, management control (previously managerial control and employment equity), skills development, enterprise and supplier development (previously preferential procurement and enterprise development) and socioeconomic development (Department of Trade and Industry, 2013). This study focused on two elements, namely management control and employment equity.

Black managers in higher positions "job-hop" from one company to another or start their own businesses when companies fail to provide for their career development (Nzukuma \& Bussin, 2011). Also, entrepreneurism is stimulated by other pillars of the BBBEE Act, namely preferential procurement and enterprise development (Nzukuma \& Bussin, 2011).

Andreeva (as cited in Ivanova, 2005, p. 72) defined the crisis of social identity "as a state of consciousness in which most of the social categories by means of which an individual defines himself and his place in society, seem to have lost their boundaries and their value". Post-apartheid, the re-evaluation of identity caused the South African society to accept new values. This crisis of identity does not only occur when individuals face loss of status and opportunity in their newly assigned space in society (Ivanova, 2005; Korostelina, 2003; Malanchuk, 2005), but also in cases where they gain status and opportunity (Herriot \& Scott-Jackson, 2002). Thus, in accordance with such cultural environment, black executives taking up senior roles are expected to fit into a culture that will never fully accept them (Fernandez \& Alsaeed, 2014). This is due to the legacy of apartheid and racial profiling which reserved jobs for whites and expected the discriminated to foster new values rather than gain respect for their own.

According to Vass (2010), South African companies focus mainly on meeting legislative compliance by chasing targets instead of embracing transformation as a strategic imperative. Companies, therefore, seek quick fixes like head hunting, poaching and salary incentives to achieve their targets. When blacks are appointed in top management positions, it is often in "soft jobs" with limited authority and minimal career prospects. Equity legislation and the emigration of skilled labour also force companies to chase targets, resulting in the mobility of black talent and a "war" for a limited pool of black professionals (Nzukuma \& Bussin, 2011). According to Booysen (2006), whites generally perceive blacks as incapable, despite the experiences, skills, and degrees they 
may attain.

Whites, even as a minority which held absolute power previously, still hold the most economic and management power. Despite the presence of blacks in the political dynamics, they are yet to achieve some power in the context of management or organisations (Booysen, 2007).

\subsection{Legislative Framework}

The introduction of the Employment Equity Act, BBBEE Act, Skills Development Act and various charters stipulate the levels of empowerment required within various industries to drive transformation and the economic empowerment of those who were disenfranchised because of apartheid (Employment Equity Report, 2011).

The Department of Trade and Industry (DTI) enforces codes through the BBBEE Act which stipulate the compliance targets of black management control at board and top-management levels of $50 \%$ and $40 \%$ respectively, to be attained by 2014 (Department of Trade and Industry, 2007). The codes stipulate an Employment Equity target of 43\% to be achieved between 2007 and 2012, and 60\% between 2012 and 2016 for senior management (Department of Trade and Industry, 2007).

\subsection{Directorship Appointments}

In 1992, the top 100 JSE-listed companies had 1173 board directors (Jack, Wu, Makhari, \& Lorio, 2004). Fewer than 15 individuals $(1.2 \%)$ were black. In 1997, the number of black directors increased to 100, increasing the ratio of black executive directors to 1:3 from 1:14 in 1992. Black managers in the private sector are few, with even fewer in positions that are in control of capital (Tangri \& Southall, 2008).

To meet the DTI's compliance targets, companies appoint non-executive as opposed to executive black directors. This does not correspond with the true intention of the BBBEE Act, which is to drive transformation and the deracialisation of the economy (Tangri \& Southall, 2008). The literature also implies that organisations possibly "window dress" black management representation by appointing black non-executive directors to achieve BBBEE targets, while true transformation comes through executive positions.

Although, there are formal legalities that aim to focus on equality in the South African workplace, it is long road to substantially achieve equality due to the prevalence of societal discrimination and the past ideology of racial discrimination in existence. The data mentioned above certifies that despite the progress, there exists an apparent race gap at the decision-making level of management in South African organizations (Booysen, 2007).

\subsection{Cultural Impact}

Black incumbents are taking up senior roles in a corporate culture different from their own (Fernandez \& Alsaeed, 2014; Khanyile \& Maponga, 2006). Similarly, companies are not prepared to embrace black leadership as a result of their unfamiliarity with ethnically different leadership cultures (Jack et al., 2004; Vass, 2010). The research conducted by Dzivhani (2016) asserted a relationship between leadership and ethnicity. There is a large body of research that concludes the challenges faced by ethnic minorities to gain access to leadership positions (Ospina \& Foldy, 2009). According to Elliott and Smith (2004), there has been a considerable slower rate of promotion for African American managers as compared to white managers.

Staff retention and commitment are mainly driven by organisational culture. Research on South African companies shows that those companies that focus on meeting legislative compliance by developing diversity, training and development policies will drive cultural change and embrace transformation as a strategic imperative (Vass, 2010). Though the executive teams of South Africa's top 40 companies are eventually gaining representation, it's very rare that black leaders make it to the top in their companies. It is imperative for the organisations to be more strategic about transformation, if their goal is to develop a cohesive pool of different leaders (Hammer, 2015), wherein they will be placed for influential roles rather than fulfilling the obligatory mandate of BBBEE Act. Frustration with corporate culture has forced many black individuals to seek alternate employment or start their own businesses (Nzukuma \& Bussin, 2011).

\subsection{Job-hopping}

Job-hopping is defined as the frequent, voluntary mobility of individual employees from one organisation to the next, for a variety of reasons (Selome, 2010). This term was apparent in companies wherein they lost African people as quickly as they recruited them (Booysen, 2006). The Consumer Insight Agency (CIA) in South Africa conducted a study based on 60 black respondents and revealed that a lack of recognition, culture clashes, hostility at work, accusations of tokenism, "sidelining" and open resistance from line management resulted in the lack of integration of black employees into senior positions and subsequently in job hopping (Cruz, 2006). Resonating with the above line of thought, Tanski (2011) highlight other factors that lead to the trend of 
job-hopping such as the low commitment to employment equity from top management in companies, expectations of conformity of black recruits into the workplace culture, the dominant white culture that discriminates against the blacks, and little delegation of responsibility for decision making. They are some of the factors that contribute to extensive job-hopping. In addition, black managers have a personal need to be owners or entrepreneurs, and they believe that job-hopping provides them with skills and networks (Nzukuma \& Bussin, 2011). Most importantly, black managers believe that the window of opportunity of ownership only exists while "black is in fashion" and while adherence to legislation is required (Cruz, 2006). Fear of failure (Cruz, 2006), searching for "greener pastures" (Vass, 2010) and feeling disempowered, lacking cultural fit, working on insignificant projects and/or exposure to limited career planning (Pranaya, 2014) can also lead to job-hopping.

It is often argued that black professionals, as a result of transformation and the skills shortage, have an employment advantage over their white counterparts (Vass, 2010) which causes the companies to pursue head hunting, fast tracking and preferentially recruiting equity candidates. Yet, at the time of the study, Commission for Employment Equity Report (2011) reflects that whites account for $83.1 \%$ of top management positions although they constitute only $12.1 \%$ of the economically active population. Today, the latest Commission for Employment Equity Report (2017) reflects that whites account for $68.5 \%$ of top management positions although they constitute only $9.5 \%$ of the economically active population. It can therefore be deducted that very little has changed.

\subsection{Alternate Employment Opportunities}

New employment opportunities should not be seen as driving job mobility among black professionals as the employment of whites grew from $49.2 \%$ to $56.9 \%$ while African employment dropped from $50 \%$ to $41.3 \%$ in the professional and middle management band. The academic world views this as "disturbing" as this band forms the succession band for future management (Vass, 2010).

To meet their BBBEE preferential procurement and enterprise development targets (Nzukuma \& Bussin, 2011), South African companies sign contracts with black empowered companies, which should encourage black professionals to own their own businesses. Yet, a decrease in black males in top management positions has been reported (CEE Report, 2010; CEE Report, 2011; Nzukuma \& Bussin, 2011).

According to Vass (2010), senior and top management positions that were filled created a division in labour based on racial bias. Black Africans and women were placed in "soft jobs" (such as human resources, marketing, transformation and training) while white appointments occurred in strategic roles with greater authority and visible value to the organisation (Vass, 2010; Price, 2007). This results in the poor retention of black individuals (Nzukuma \& Bussin, 2011).

\subsection{Scarcity of Talent}

According to Vass (2010), the systemic failure of companies to transform should also be ascribed to the failure of an education system based on discriminatory practices. Companies should become active partners in developing skills and careers instead of opting for head hunting, poaching and unsustainable salary incentives.

Scarcity of mentorship in an organisation is a driver for human resource turnover (Payne \& Huffman, 2005). Rentilla (2006) asserted that colleagues in cross-race mentoring relationships who shared similar racial perception formulated a stronger relationship. The major drawback for blacks to evolve professionally is the lack of a proper mentor (Nzukuma \& Bussin, 2011). According to Booysen (2007), inter-group anxieties are in existence due to the discriminatory legislation and the transformation won't come till efforts are made. Such slow pace or lack of transformation frustrates the blacks (Booysen, 2006).

The scarcity of black talent within the JSE listed companies, equity legislation and the emigration of skilled labour have resulted in companies chasing numbers, which force black talent to be mobile (Nzukuma \& Bussin, 2011). Human resource practitioners say the "war" for black professionals is fuelled by democracy, affirmative action and a skills crisis. Succession planning and internal career advancement should be part of the development plan to drive internal upward mobility (Vass, 2010). The lack of career path development contributes to the outward mobility or job-hopping of black managers (Nzukuma \& Bussin, 2011).

\subsection{The International Context}

\subsubsection{Leadership Transition}

Leadership behaviours and styles across cultures have similarities as well as differences (Russette, Scully \& Preziosi, 2008). Therefore, leadership transition in a new position is vulnerable in the first few months. In one study, "being isolated" ranked as the top issue for leaders in a transition period (Appelbaum \& Valero, 2007). 
The first exposure of black managers is therefore critical to ensure smooth leadership transition. Senior black leaders can be "surprised" when they find out that they have less formal power to make decisions than they originally thought (Shaw \& Chayes, 2011).

Employee recognition drives growth, transformation and organisational performance (Brun \& Dugas, 2008). The second largest factor for psychological distress in the workplace is the lack of recognition, which can lead to job dissatisfaction (Brun \& Biron, 2003). Critical success factors in dealing with transition therefore include leadership confidence, recognition and the ability to deal with uncertainty and complexity (Shaw \& Chayes, 2011).

\subsubsection{Transactional and Transformational Leadership}

A focus area of this study is understanding strategic leadership behaviours and its influence on leadership integration. There is a difference between transactional and transformational leadership (Elenkov, Judge, \& Wright, 2005; Ng \& Sears, 2012). Hargis, Watt and Piotrowski (2011) mentions in terms of team effectiveness and management by exception, transformational leadership dominates transactional leadership behaviours. In South African companies, leadership behaviour resembles that of transactional leadership as companies focus on numerical targets rather than organisational transformation (Vass, 2011; Ng \& Sears, 2012; Leonard \& Grobler, 2006).

Transformational leaders enhance performance in environments that are dynamic and unstable (Vasilaki, 2011), and they focus more strongly on the implementation of diversity practices (Ng \& Sears, 2012). Transformational leaders operate with a greater sense of social responsibility and a spirit of inclusivity (Nishii \& Mayer, 2009). These leaders also believe that the management of diversity comes with legal and moral obligations (Leonard \& Grobler, 2006). Transactional leaders, on the other hand, follow rules and comply with diversity requirements only to avoid punitive measures (Hood, 2003).

\subsubsection{Cultural Impact}

The ability to be culturally aware of the behaviours, qualities, skills, attitudes and values of others is called cultural intelligence (Sozbilir \& Yesil, 2016). This generates an assumption whether in South African companies, the integration of black leadership failed due to the lack of cultural intelligence among both black and white executives. South African companies have a collectivist cultural context compared to Western companies which have individualistic culture and therefore, the management has the daunting task of reconciling these two cultural context (Zakaria, Abdul-Talib, \& Osman, 2016).

\subsubsection{Diversity}

The dimensions of diversity include language, race, ethnicity, gender, beliefs, age, disabilities, socio-economic standing and sexual orientation (Patrick, 2011; Dreachslin, 2008). Companies are cautious to engage with diversity as they feel it will alienate existing employees and increase costs (Ouseley, 2006). For others, recruitment and retention is a challenge as talented employees are poached, and when coupled with scarcity of equity candidates to promote, they resort to soft placements (Ouseley, 2006).

The age of leaders can influence their views on diversity (George \& Yancey, 2004). A correlation between age and leadership is seen in attributes such as empathy, foresight, persuasion and stewardship, with older people needing stronger motivation to embrace diversity (McCuddy \& Calvin, 2009). Social values and age are the two moderating factors that drive diversity implementation (Ng \& Sears, 2012).

\section{Research Design}

\subsection{Research Approach}

A quantitative method was chosen as existing theories are utilised to answer the research question (Sun, 2009) and the interrelationships between the chosen variables (Creswell, 2001). According to Terre Blanche, Durheim and Painter (2007), a research design is the strategic framework that converts the research questions into operational questions. The descriptive study utilised a questionnaire to elicit the opinions, observations, characteristics and attitudes of the participants towards the chosen set of variables (Sun, 2009).

The questionnaire containing quantitative questions covered all variables identified during the literature search. A pilot study was conducted to ensure content and construct validity of the questionnaire. The pilot study provides an external perspective, ensuring clarity and intent of the questionnaire and to improve the validity of the content (Creswell, 2006; Sun, 2009). A quantitative research discipline was chosen to ensure rigour in terms of verifiability, reliability and generalizability (Meadows, 2003). 


\subsection{Population and Sampling}

The survey population consisted of 1637 black and white top and senior executives from approximately 330 companies represented on the executive committee and/or board of a JSE-listed company in South Africa (as at 18 May 2012). These companies are required by law to adhere to BBBEE Act 53 of 2003 (Act, 2004).

Probability sampling was used in order to reflect the relevant population. Random sampling provides an equal chance to all participants from the target pollution (Meadows, 2003).

The first step is to identify participating companies listed on the main board of the Johannesburg Securities Exchange (JSE). The Johannesburg Securities Exchange (JSE) provided a cluster sample of all potential participating companies; as only South African companies listed on the main board of the JSE was extracted and eligible for the study (Meadows, 2003). The sample size of companies listed on the JSE is approximately 330 companies.

The second step is to build a database of willing companies and individual participants. A database of potential participants from a total of 330 companies was identified through the company website, annual statutory reports, or where companies were contacted directly and were willing to participate and provide contact details of top and senior management. The database consists of approximately 1637 top and senior management information that were relevant to this study. The database was built in collaboration between the researcher and a contracted agency.

\subsection{Data Collection}

The survey participants' demographic information was based on gender, citizenship, level within the organisation, age, race, education and length of service in previous and current jobs. Demographic information is segmented into white and black participants. Black participants refer to African, Coloured and Indian participants. Data was collected through an electronic questionnaire utilising Questback ${ }^{\mathrm{TM}}$. A link to the questionnaire was sent via email. Participation was anonymous and voluntary.

Some limitations were experienced from the 330 companies listed on the main board of the Johannesburg Securities Exchange (JSE). According to the contracted agency SPDS (PTY) Ltd, responses received indicated that companies did not have the time to provide the information, or they do not give out non-public information, or they are simply not interested and many failed to respond in spite of many phone calls and email requests by the contracted agency.

The instrument consists of a survey in the form of a closed ended questionnaire using a Likert scale. The questionnaire comprises of 4 sections. Section A consists of background and biographical information. Section B utilises a pre-validated questionnaire developed by Hackman-Oldham called the Revised Job Diagnostic Survey (JDS) to measure job satisfaction and growth satisfaction (career development opportunities). The Revised Job Diagnostic Survey (JDS) is a reliable and factorially valid instrument for South African use (Buys, Olckers, \& Schaap, 2007). Section C uses a pre-validated questionnaire developed in conjunction with Mindgarden Inc. (USA). The questions were adopted from the Multifactor Leadership Questionnaire MLQ 5X short, the most widely used in the measurement of both transactional and transformational leadership (Tejeda et al., 2001) which in the latest version 3 contains 45 items measuring leadership behaviours that can be divided into 9 characteristics and 3 leadership outcomes (Bass \& Avolio, 1994). According to Mindgarden Inc. (USA), the latest version of the MLQ, Form 5X, has been used by management in both Fortune 500 and Fortune 1000 companies in multiple languages, and in approximately 300 research programs, doctoral dissertations and masters theses around the world (Bass \& Avolio, 1994). The factor structure of MLQ 5X was validated by both discriminatory and confirmatory factor analysis (Bass \& Avolio, 1994). In collaboration with Mindgarden Inc. (USA), the questionnaire was adjusted to meet the requirements of the study maintaining its integrity as a validated form. Section D consists of questions developed based on the outcome of the literature review. Section D will be validated utilising factor analysis and Cronbach's alpha is used to measure reliability.

Table 1. Cronbach's alpha rating scale

\begin{tabular}{ll}
\hline Scale & Rating \\
\hline$>0.90$ & Excellent \\
$0.80-0.89$ & Good \\
$0.70-0.79$ & Acceptable \\
$0.60-0.69$ & Questionable \\
$0.50-0.59$ & Poor \\
$<0.50$ & Unacceptable \\
\hline
\end{tabular}




\subsection{Data and Statistical Analysis Tools}

Data analysis will utilize descriptive analysis, correlation analysis, regression analysis and factor analysis. Descriptive analysis will be used to understand the demographics (personal profile, age, education levels, race and ethnicity) of the sample. Correlation analysis is used to test if a significant relationship exists between the independent variables (key critical success factors) and the dependent variables (measures of successful leadership integration). Regression analysis is in particular useful in identifying those predictors that will maximise the degree of the variance explained in the criterion (Lind, Marchall, \& Wathen, 2011). Factor Analysis will provide validity to each of the factors referred to in Section D of the questionnaire (Antonakis et al., 2003).

\subsubsection{Ethical Considerations}

Hunter and Dantzker (2011) explain that exploration morals incorporate the utilization of essential good models to blended perspectives of focuses including examination, including legitimate investigation. These join the framework and execution of investigation including human experimentation, creature experimentation, diverse parts of insightful humiliation, including investigative terrible conduct, regulation of investigation and so on. Researchers face moral circumstances in every progression of the exploration process from picking members to report findings at the end of the study. Maxcy (2003) explains consequently, to effectively finish the examination prepare, each researcher needs to run over the moral issues included and meet the ethics as well. The investigator ensured the ethical considerations of the research as participation was voluntary, confidential and anonymous. The survey was conducted by an independent third party to ensure integrity and quality and where responses could not be linked back to any individual. 4. Research Findings

\subsection{Analysis of Critical Success Factors}

Elenkov et al. (2005) refer to various researchers who believe that managerial level factors, organisational characteristics and environmental factors represent the main antecedents to organisational innovation and development. In the table below (Table 2), the 32 constructs identified in the literature review have been grouped according to these antecedents (Elenkov et al., 2005).

Table 2. Summary of 32 constructs grouped according to managerial level factors, organisational characteristics and environmental factors

\begin{tabular}{lll}
\hline Managerial-level factors & Organisational characteristics & Environmental factors \\
\hline Remuneration & Tokenism/soft placement & Employment equity (legislation) \\
Job satisfaction & Mentoring and coaching & War for talent \\
Age & Community involvement & Limited pool of black talent \\
Confidence & Cultural diversity & Discrimination (racial and gender profiling) \\
Fear of failure & "Soft jobs" & Job-hopping \\
Behavioural characteristics & Commitment to transformation & \\
Entrepreneurship & "Sidelining" & \\
Owning own business & Leadership styles & \\
Autonomy/independence & Language barrier & \\
Personal values & Fear of employment equity & \\
Career development & Cultural intelligence & \\
& Ethnic diversity & \\
& Training & \\
& Recognition & \\
& Inner circles and hidden & \\
& Hierarchies & \\
& Open resistance by line & \\
& management & \\
\hline
\end{tabular}

Next, the 32 constructs that influence the selected variables (leadership style, strategic leadership behaviours, tenure, job satisfaction, culture, ethnicity and growth satisfaction) were linked to the research questions developed for the questionnaire. This rendered the following results: 
- Job satisfaction, career development and leadership behaviours (MLQ 5X): Cronbach's alpha for job satisfaction was good (0.836) and for career development (0.767) it was rated as acceptable (George \& Mallery, 2003). The leadership style and behaviour scores, ranging from 0.542 to 0.645 , based on the MLQ $5 \mathrm{X}$ were low. However, all scores were positive.

- Fair treatment, job-hopping, commitment to transformation, black entrepreneurship and corporate culture: White managers identified four primary constructs while black managers identified three primary constructs based on factor analysis. For responses identified by white management, two of the four constructs displayed good Cronbach's alpha (fair treatment [0.834] and job hopping [0.801]), one displayed acceptable Cronbach's alpha (commitment to transformation [0.732]) while the last one displayed an unacceptable yet positive Cronbach's alpha (black entrepreneurship [0.473]). For responses identified by black management, two of the three constructs showed acceptable Cronbach's alpha (fair treatment [0.833] and job hopping [0.822]) while one had a marginal Cronbach's alpha (corporate culture [0.653]).

Based on the literature review, 32 questions were formulated to measure the participants' general and organisational perception of critical success factors that influence leadership integration. A 7-point Likert scale was used to measure respondents' agreement (see Figure 1 below).

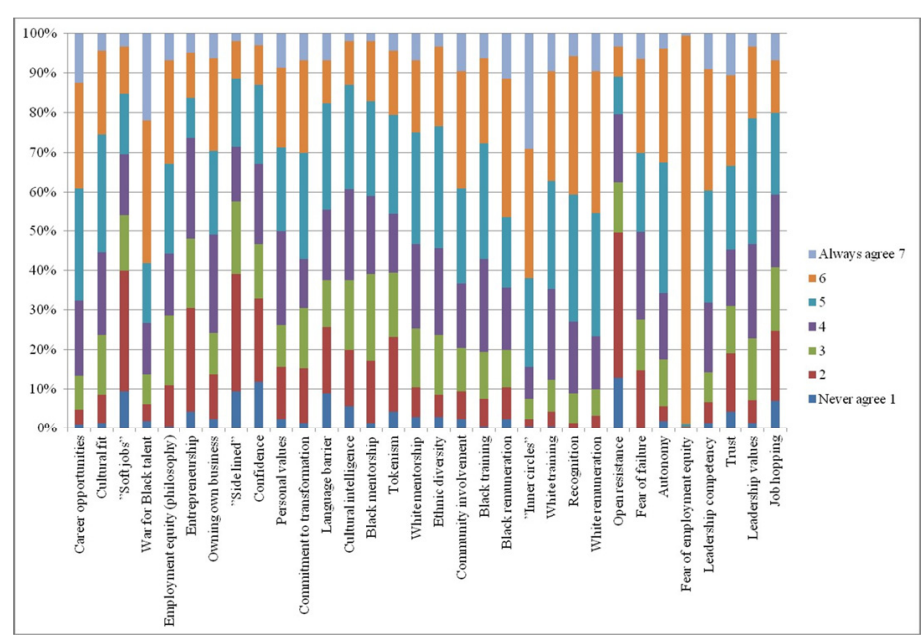

Figure 1. Possible critical success factors influencing black leadership integration

The top five constructs identified by all participants revealed that $84 \%$ agree that inner circles exist in organisations, $77 \%$ agree that white management fear employment equity, $77 \%$ agree that white management's remuneration is fair, $73 \%$ agree that black managers are mobile as a result of the limited pool of black talent, and $73 \%$ agree that line management provides recognition for a job well done. Based on the bottom five constructs, $20 \%$ of the participants agree that resistance exists between executive line management and reporters where race differs, $29 \%$ agree that black managers are often "sidelined", 30\% agree that black managers are predominantly offered "soft jobs", 26\% agree that black managers become entrepreneurs as a result of frustration with corporate culture, and 33\% agree that black managers lack confidence to deal with increasing role complexity.

\subsection{Outcomes of Factor Analysis}

Factor analysis is a statistical tool identifying variables that are similar and correlate with each other thereby identifying latent variables that are inherent in the total set of variables observed (De, 2011). According to Gosh (2011) factor analysis is a statistical technique that examines underlying factors or constructs on a number of measured variables. In this study exploratory factor analysis is applied to the 32 questions developed from the literature review. Through parallel analysis utilizing a scree plot White management identified four primary factors based on the factor loadings, while Black management identified three primary factors based on the factor loadings.

Table 3 shows the definition allocated to each primary together with the relevant question and question numbers based on the responses received from White management. 
Table 3. Primary constructs - description and loaded questions for white management

\begin{tabular}{|c|c|}
\hline & 1. Black management is provided with adequate career development opportunities. \\
\hline & 14. Black managers in general receive adequate mentoring. \\
\hline & 16. White managers in general receive adequate mentoring. \\
\hline \multirow[t]{2}{*}{ Primary 1} & 18. Organisations adequately take part in community based projects. \\
\hline & 19. Black managers in general receive adequate training. \\
\hline \multirow[t]{6}{*}{ Fair treatment } & 20. The remuneration Black managers receive for their job is fair. \\
\hline & 22. White managers in general receive adequate training \\
\hline & 23. Line management provide recognition for a job well done. \\
\hline & 24. The remuneration White managers receive for their job is fair. \\
\hline & 3. Black managers are predominantly offered "soft jobs" that have limited authority. \\
\hline & 4. Black managers are mobile because there is a "war" for the limited pool of qualified Black talent. \\
\hline \multirow{2}{*}{ Primary 2} & 9. Black managers lack confidence to deal with increasing role complexity. \\
\hline & 10. Personal values of Black leaders influence a Black leader's integration into an organisation. \\
\hline \multirow{6}{*}{ Job hopping } & 15. Organisations resort to "soft placements"/ tokenism to meet equity targets by employing Black people. \\
\hline & 25. Open resistance exists between executive line management and report where race differs. \\
\hline & 28. White management fear Employment Equity. \\
\hline & 29. Black managers have adequate leadership competency. \\
\hline & 30. Generally a lack of trust exists between different cultures. \\
\hline & 5. Organisations are committed to the philosophy of Employment Equity. \\
\hline Primary 3 & $\begin{array}{l}\text { 11. South African leaders are committed to organisational transformation in terms of Broad Based Black } \\
\text { Economic Empowerment Act. }\end{array}$ \\
\hline \multirow{5}{*}{$\begin{array}{l}\text { Commitment } \\
\text { transformation }\end{array}$} & 17. Senior management value ethnic diversity. \\
\hline & 18. Organisations adequately take part in community based projects. \\
\hline & 27. Black management have adequate autonomy in their job. \\
\hline & 31. In general corporate culture and individual leadership values are Congruent \\
\hline & 6. Black managers become entrepreneurs as a result of frustration with corporate culture. \\
\hline \multirow[t]{2}{*}{ Primary 4} & 7. Black managers opt to own their own business due to opportunities provided by the Broad Based Black \\
\hline & Economic Empowerment Act? e.g. Preferential Procurement and/or Enterprise Development. \\
\hline \multirow[t]{2}{*}{ Black entrepreneurship } & 8. Black managers are often "sidelined". \\
\hline & 32. Job hopping is due to the lack of career development opportunities. \\
\hline
\end{tabular}

Table 4 shows the definition allocated to each primary together with the relevant question and question numbers based on the responses received from Black management.

Table 4. Primary constructs - description and loaded questions for black management

1. Black management are provided with adequate career development opportunities.

5. Organisations are committed to the philosophy of Employment Equity.

11. South African leaders are committed to organisational transformation in terms of Broad Based Black Economic Empowerment Act.

13. Management in general are culturally tuned to the concept of cultural Intelligence i.e. certain behaviours, qualities, attitudes and values of others.

Primary 1

14. Black managers in general receive adequate mentoring

Fair treatment

17. Senior management value ethnic diversity.

18. Organisations adequately take part in community based projects.

19. Black managers in general receive adequate training.

20. The remuneration Black managers receive for their job is fair.

23. Line management provide recognition for a job well done.

24. The remuneration White managers receive for their job is fair.

27. Black management have adequate autonomy in their job.

31. In general corporate culture and individual leadership values are congruent.

Primary 2 3. Black managers are predominantly offered "soft jobs" that have limited authority.

Job hopping 8. Black managers are often "sidelined". 


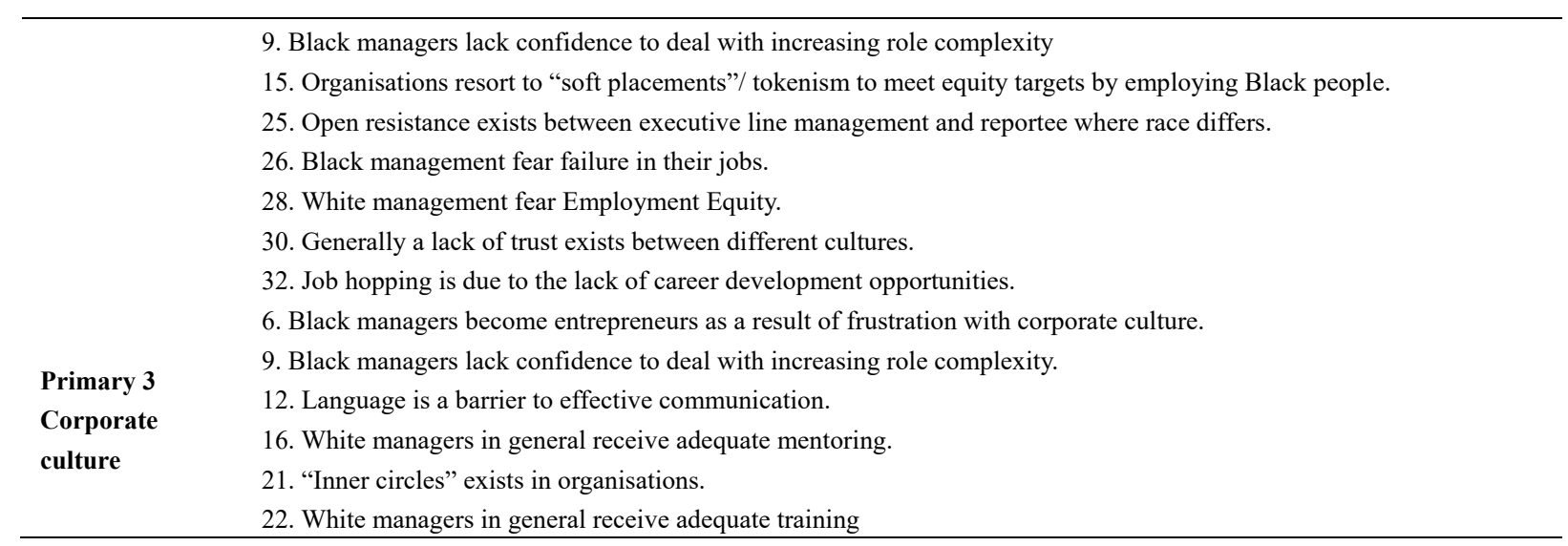

Eigenvalues were computed to identify the cumulative percentage variance for the four primary factors identified by White management and the three primary factors identified by Black management. Eigenvalues measure the total variance in a group of variables that is explained by a particular factor. A guideline is to use factors with an eigenvalue greater than 1 (Pallant, 2007 and Costello \& Osborne, 2005).

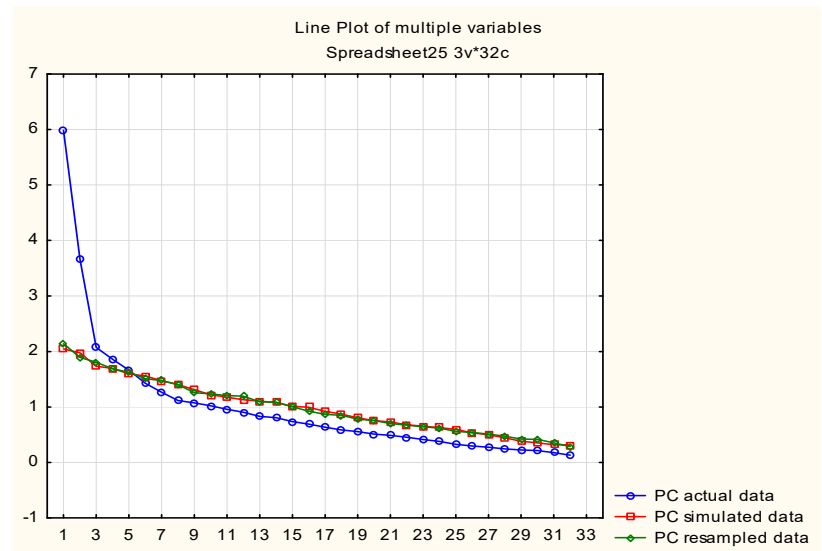

Figure 2. Screen Plot: Identification of factor loadings by White management

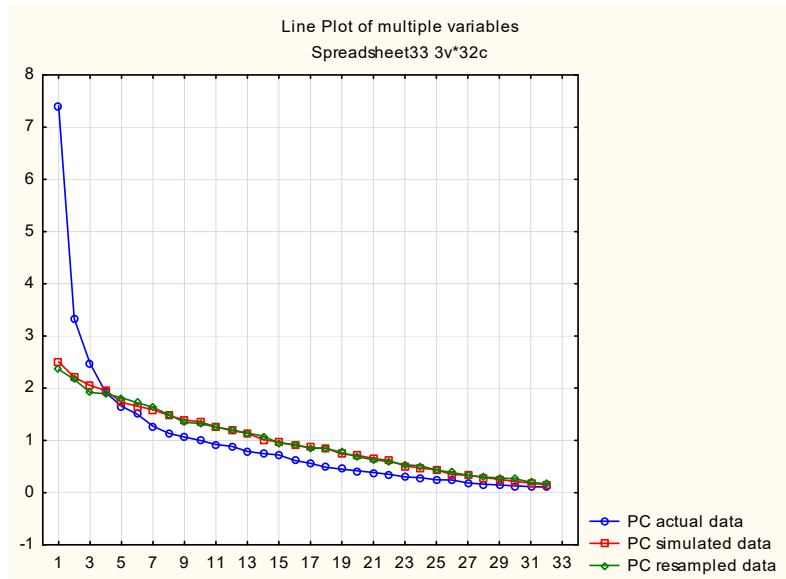

Figure 3. Scree Plot: Identification of factor loadings by Black management 
Table 5. Eigen Values: Identification of factor loadings by White management

\begin{tabular}{lllll}
\hline Value & Eigenvalue & \% Total Variance & Cumulative Eigenvalue & Cumulative Percentage \\
\hline 1 & 5.985 & $18.7 \%$ & 5.985 & $18.7 \%$ \\
2 & 3.664 & $11.4 \%$ & 9.649 & $30.1 \%$ \\
3 & 2.073 & $6.4 \%$ & 11.723 & $36.6 \%$ \\
4 & 1.860 & $5.8 \%$ & 13.583 & $42.4 \%$ \\
\hline
\end{tabular}

Table 6. Eigen Values: Identification of factor loadings by Black management

\begin{tabular}{lllll}
\hline Value & Eigenvalue & \% Total Variance & Cumulative Eigenvalue & Cumulative Percentage \\
\hline 1 & 7.408 & $23.1 \%$ & 7.408 & $23.1 \%$ \\
2 & 3.328 & $10.4 \%$ & 10.737 & $33.5 \%$ \\
3 & 2.471 & $7.7 \%$ & 13.209 & $41.2 \%$ \\
\hline
\end{tabular}

According to Brown (2009) rotation is a process designed to identify simple structures. Rotation methods are either orthogonal or oblique. Orthogonal rotation assumes that the factors that are analysed are uncorrelated while oblique rotation assumes that the factors been analysed are correlated (Brown, 2009). According to Brown (2009) it is useful to try one orthogonal method and one oblique method to in order to examine for a simple structure. According to Costello and Osborne (2005), when the same extraction method is used and the oblique rotation reproduces the oblique rotation then the oblique rotation is recommended. Following the rotation method, below is the rank order of variables which are the outcomes of the factor analysis:

\section{Highest loaded factor - fair treatment:}

Black managers described this as the provision of adequate career development opportunities, recognition, mentoring, training and remuneration. For black managers, fair treatment includes organisational commitment to transformation in terms of employment equity and BBBEE, cultural intelligence, the valuing of ethnic diversity and autonomy.

\section{Second highest loaded factor - fair treatment:}

White managers described this as the provision of adequate career development opportunities, recognition, mentoring, training and remuneration.

\section{Third highest loaded factor - job-hopping:}

Job-hopping according to white management is a result of black managers placed in "soft jobs" with limited authority, a "war" for a limited pool of black talent, lack of confidence in dealing with complexity, adequate leadership competency, personal values, tokenism, open resistance between executive and line management, and the lack of trust.

\section{Fourth highest loaded factor - job-hopping:}

Job-hopping according to black management is a result of black managers being placed in "soft jobs" with limited authority, lack of confidence in dealing with complexity, tokenism, and resistance between executive and line management. Black managers also say job-hopping is a result of fear of failure and the lack of career development opportunities.

\section{Fifth highest loaded factor - corporate culture:}

For black managers, corporate culture refers to frustration in the organisation that drives black entrepreneurship, leadership that does not stimulate confidence in black management to deal with complexity, "inner circles" and language barriers. Black managers believe that South African corporations provide adequate mentorship and training to white management.

\section{Sixth highest loaded factor - commitment to transformation:}

For white managers, commitment to transformation refers to employment equity, BBBEE, the valuing of diversity, the support of community-based organisations and the provision of autonomy to black management.

\section{Seventh highest loaded factor - black entrepreneurship:}

White managers describe black entrepreneurship as black managers leaving the organisation as a result of frustration with corporate culture (which leads to black managers opening up their own businesses to benefit 
from BBBEE opportunities), "sidelining" and the lack of career development opportunities.

\subsection{Hypothesis Testing}

Spearman's Rank Coefficient is a nonparametric measure of statistical dependence between two variables in their respective samples. Spearman's coefficient lies between -1 and +1 , where -1 or +1 denotes a straight line relationship between the two variables. 0 depicts no correlation between the two variables. Spearman's coefficient is represented by $\mathrm{r}_{\mathrm{s}}$ (Defusco, McLeavey, Pinto, \& Runkle, 2012). Correlation analysis was conducted at a $95 \%$ confidence interval $(\alpha=0.05)$. See Tables 10 to 37 for the statistical correlation between the variables and the acceptance and rejection of different hypothesis devised.

In accordance with the correlation analysis conducted, the existence of following hypothesis is justified (see Tables 10 to 37):

For the testing of Hypothesis 1, that is, to verify the existence of a statistical correlation between critical success factors and tenure in the previous job, the following sub-hypothesis has been created:

- H1a: A statistical correlation exists between fair treatment and tenure in the previous job.

Correlation analysis was conducted between fair treatment and tenure in the previous job. As per the statistical result, H1a is rejected, and therefore, there is no correlation between fair treatment and tenure in the previous job as defined by Black and White management.

- H1b: A statistical correlation exists between job hopping and tenure in the previous job.

Correlation analysis was conducted between job hopping and tenure in the previous job. As per the statistical result, $\mathrm{H} 2 \mathrm{~b}$ is rejected, and therefore, there is no correlation between job hopping and tenure in the previous job as defined by Black and White management.

- H1c: A statistical correlation exists between commitment to transformation and tenure in the previous job.

Correlation analysis was conducted between commitment to transformation and tenure in the previous job. As per the statistical analysis, $\mathrm{H} 2 \mathrm{c}$ is rejected, and therefore, there is no correlation between commitment to transformation and tenure in the previous job as defined by White management.

- H1d: A statistical correlation exists between corporate culture and tenure in the previous job.

Correlation analysis was conducted between corporate culture and tenure in the previous job. As per the statistical analysis, $\mathrm{H} 2 \mathrm{~d}$ is rejected, and therefore, there is no correlation between corporate culture and tenure in the previous job.

- H1e: A statistical correlation exists between black entrepreneurship and tenure in the previous job.

Correlation analysis was conducted between black entrepreneurship and tenure in the previous job. As per the statistical analysis, $\mathrm{H} 2 \mathrm{e}$ is rejected, and therefore, there is no correlation between black entrepreneurship and tenure in the previous job.

For the testing of Hypothesis 2, that is, to verify the existence of a statistical correlation between critical success factors and tenure in the current job, the following sub-hypothesis has been created:

- H2a: A statistical correlation exists between fair treatment and tenure in the current job.

Correlation analysis was conducted between fair treatment and tenure in the current job. As per the statistical analysis, $\mathrm{H} 2 \mathrm{a}$ is rejected, and therefore, no correlation exists between fair treatment and tenure in the current job as defined by White management. For black management, this sub-hypothesis (H2a) is accepted, as there exists a statistical correlation between fair treatment and tenure in the current job.

- H2b: A statistical correlation exists between job hopping and tenure in the current job.

Correlation analysis was conducted between job hopping and tenure in the current job. As per the statistical analysis, $\mathrm{H} 2 \mathrm{~b}$ is rejected, and therefore, no correlation exists between job hopping and tenure in the current job as defined by White and Black management.

- H2c: A statistical correlation exists between commitment to transformation and tenure in the current job.

Correlation analysis was conducted between commitment to transformation and tenure in the current job. As per the statistical analysis, $\mathrm{H} 2 \mathrm{c}$ is accepted, and therefore, correlation exists between commitment to transformation and tenure in the current job as defined by White management.

- H2d: A statistical correlation between corporate culture and tenure in the current job.

Correlation analysis was conducted between corporate culture and tenure in the current job. As per the statistical 
analysis, $\mathrm{H} 2 \mathrm{~d}$ is rejected, and therefore, no correlation exists between corporate culture and tenure in the current job as defined by Black management.

- H2e: A statistical correlation exists between black entrepreneurship and tenure in the current job.

Correlation analysis was conducted between black entrepreneurship and tenure in the current job. As per the statistical analysis, $\mathrm{H} 2 \mathrm{e}$ is rejected, and therefore, no correlation exists between black entrepreneurship and tenure in the current job as defined by White management.

For the testing of Hypothesis 3, that is, to verify the existence of a statistical correlation between critical success factors and job satisfaction, the following sub-hypothesis has been created:

- H3a: A statistical correlation exists between fair treatment and job satisfaction

Correlation analysis was conducted between fair treatment and job satisfaction. As per the statistical analysis, H3a is accepted, and therefore, correlation exists between fair treatment and job satisfaction as defined by White and Black management.

- H3b: A statistical correlation exists between job hopping and job satisfaction.

Correlation analysis was conducted between job hopping and job satisfaction. As per the statistical analysis, $\mathrm{H} 3 \mathrm{~b}$ is rejected, and therefore, no correlation exists between job hopping and job satisfaction as defined by White management. For Black management, this sub-hypothesis (H3b) is accepted as there lies a correlation between job hopping and job satisfaction.

- $\quad \mathrm{H} 3 \mathrm{c}$ : A statistical correlation exists between commitment to transformation and job satisfaction.

Correlation analysis was conducted between commitment to transformation and job satisfaction. As per statistical analysis, $\mathrm{H} 3 \mathrm{c}$ is accepted, and therefore, correlation exists between commitment to transformation and job satisfaction as defined by White management.

- H3d: A statistical correlation exists between corporate culture and job satisfaction.

Correlation analysis was conducted between corporate culture and job satisfaction. As per the statistical analysis, $\mathrm{H} 3 \mathrm{~d}$ is accepted, and therefore, correlation exists between corporate culture and job satisfaction as defined by Black management.

- H3e: A statistical correlation exists between black entrepreneurship and job satisfaction.

Correlation analysis was conducted between black entrepreneurship and job satisfaction. As per the statistical analysis, H3e is rejected, and therefore, no correlation exists between black entrepreneurship and job satisfaction as defined by White management.

For the testing of Hypothesis 4, that is, to verify the existence of a statistical correlation between critical success factors and career development, the following sub-hypothesis has been created:

- H4a: A statistical correlation exists between fair treatment and career development.

Correlation analysis was conducted between fair treatment and career development. As per the statistical analysis, $\mathrm{H} 4 \mathrm{a}$ is accepted, and therefore, correlation exists between fair treatment and career development as defined by Black and White management.

- H4b: A statistical correlation exists between job hopping and career development.

Correlation analysis was conducted between job hopping and career development. As per the statistical analysis, $\mathrm{H} 4 \mathrm{~b}$ is rejected and therefore, no correlation exists between job hopping and career development as defined by White management. For Black management, this sub-hypothesis $(\mathrm{H} 4 \mathrm{~b})$ is accepted as correlation exists between job hopping and career development.

- H4c: A statistical correlation exists between commitment to transformation and career development.

Correlation analysis was conducted between commitment to transformation and career development. As per statistical analysis, $\mathrm{H} 4 \mathrm{c}$ is accepted and therefore, correlation exists between commitment to transformation and career development as defined by White management.

- H4d: A statistical correlation exists between corporate culture and career development.

Correlation analysis was conducted between corporate culture and career development. As per the statistical analysis, $\mathrm{H} 4 \mathrm{~d}$ is rejected and therefore, no correlation exists between corporate culture and career development as defined by Black management.

- H4e: A statistical correlation exists between black entrepreneurship and career development. 
Correlation analysis was conducted between black entrepreneurship and career development. As per the statistical analysis, $\mathrm{H} 4 \mathrm{e}$ is rejected and therefore, no correlation exists between black entrepreneurship and career development as defined by White management.

\subsection{Outcomes of Simple Correlation Analysis and Multiple Regression Analysis}

Simple correlation analysis was used to identify critical success factors that influence black leadership integration from the perspectives of white and black managers. The influencing factors that are common perspectives of both groups are fair treatment and job satisfaction, fair treatment and career development, job satisfaction and leadership styles and behaviour, and career development and leadership styles and behaviour.

Table 7 represents the findings from simple correlation analysis, identifying critical success factors that influence Black leadership integration, from a White management perspective, from a Black management perspective and influencing factors that are common perspectives of both Black and White management groups (depicted in bold font).

Table 7. Summary outcomes of simple correlation analysis

\begin{tabular}{|c|c|}
\hline Black Management & White Management \\
\hline \multicolumn{2}{|l|}{ Fair treatment and tenure in current job } \\
\hline Career development and tenure in current job & Fair treatment and job satisfaction \\
\hline Job satisfaction and tenure in current job & Fair treatment and career development \\
\hline Fair treatment and job satisfaction & Fair treatment and idealised influence (behaviour) \\
\hline Fair treatment and career development & Job hopping and idealised influence (attributed) \\
\hline Fair treatment and inspirational motivation & Commitment to transformation and tenure in current job \\
\hline Job hopping and job satisfaction & Commitment to transformation and job satisfaction \\
\hline Job hopping and career development & Commitment to transformation and career development \\
\hline Job hopping and idealised influence (behaviour) & Commitment to transformation and leadership styles and behaviour* \\
\hline Job hopping and inspirational motivation & $\begin{array}{l}\text { Job satisfaction and leadership styles and behaviour } * * * * \\
\text { Career development and leadership styles and behaviour } * * * * *\end{array}$ \\
\hline \multicolumn{2}{|l|}{ Corporate culture and job satisfaction } \\
\hline \multicolumn{2}{|l|}{ Corporate culture and inspirational motivation } \\
\hline \multicolumn{2}{|c|}{ Job satisfaction and leadership styles and behaviour** } \\
\hline \multicolumn{2}{|c|}{ Career development and leadership styles and behaviour*** } \\
\hline \multicolumn{2}{|c|}{$\begin{array}{l}\text { Notes. *Contingent reward, Management-by-exception (active), Idealised influence (behaviour), Inspirational motivation, Idealised influenc } \\
\text { (attributed) and individual consideration }\end{array}$} \\
\hline \multicolumn{2}{|c|}{ **Contingent reward, Idealised influence (behaviour), Inspirational motivation } \\
\hline \multicolumn{2}{|c|}{$* * *$ Contingent reward, Idealised influence (behaviour), Inspirational motivation and Individual consideration } \\
\hline ****Intellectual stimulation, Idealised influence (b & spirational motivation, Idealised influence (attributed) \\
\hline
\end{tabular}

The research outcomes from simple correlation analysis was refined through the use of multiple regression analysis, as observed in Table 8, which identifies those critical success factors that influence Black leadership integration, from a White management perspective, from a Black management perspective and influencing factors that are common perspectives of both Black and White management groups (depicted in bold font). Using multiple regression analysis, the influencing factors that are common perspectives of both groups are fair treatment and career development.

Table 8. Summary outcomes of multiple regression analysis

\begin{tabular}{ll}
\hline Black Management & White Management \\
\hline Fair treatment and tenure in current job & Fair treatment and career development \\
Fair treatment and job satisfaction & Commitment to transformation and tenure in current job \\
Fair treatment and career development & \\
Career development and idealised influence (attributed) & \\
\hline
\end{tabular}

The research outcomes from both the simple correlation analysis and multiple regression analysis was further 
refined through the use of best subset regression analysis, as observed in Table 9, which identifies those particular critical success factors that influence Black leadership integration, from a White management perspective, from a Black management perspective and influencing factors that are common perspectives of both Black and White management groups (depicted in bold font).

Table 9. Summary outcomes of best subset regression analysis

\begin{tabular}{ll}
\hline Black Management & White Management \\
\hline Job satisfaction and inspirational motivation & None \\
Fair treatment and job satisfaction & \\
Job satisfaction and idealised influence (attributed) & \\
Fair treatment and career development & \\
Career development and inspirational motivation & \\
Career development and idealised influence (attributed) & \\
\hline
\end{tabular}

\subsection{Spearman's Rank Correlation Coefficient Analysis}

Table 10. Correlation: Fair treatment (White) and job satisfaction

\begin{tabular}{llll}
\hline Variable & Count & Spearman & Spearman p-value \\
\hline Fair treatment vs. job satisfaction & 133 & 0.25 & $<0.01$ \\
\hline
\end{tabular}

Table 11. Correlation: Fair treatment (Black) and job satisfaction

\begin{tabular}{llll}
\hline Variable & Count & Spearman & Spearman p-value \\
\hline & 77 & 0.39 & $<0.01$ \\
Fair treatment vs. job satisfaction & & & \\
\hline
\end{tabular}

Table 12. Correlation: Job hopping (White) and job satisfaction

\begin{tabular}{llll}
\hline Variable & Count & Spearman & Spearman p-value \\
\hline Job hopping vs. job satisfaction & 133 & -0.15 & 0.09 \\
\hline
\end{tabular}

Table 13. Correlation: Job hopping (Black) and job satisfaction

\begin{tabular}{llll}
\hline Variable & Count & Spearman & Spearman p-value \\
\hline Job hopping vs. job satisfaction & 77 & -0.35 & $<0.01$ \\
\hline
\end{tabular}

Table 14. Correlation: Commitment to transformation (White) and job satisfaction

\begin{tabular}{llll}
\hline Variable & Count & Spearman & Spearman p-value \\
\hline & 133 & 0.30 & $<0.01$ \\
Commitment to transformation vs. job satisfaction & & & \\
\hline
\end{tabular}

Table 15. Correlation: Corporate culture and job satisfaction

\begin{tabular}{llll}
\hline Variable & Count & Spearman & Spearman p-value \\
\hline Corporate culture vs. job satisfaction & 77 & -0.24 & 0.04 \\
\hline
\end{tabular}

Table 16. Correlation: Black entrepreneurship (White) and job satisfaction

\begin{tabular}{llll}
\hline Variable & Count & Spearman & Spearman p-value \\
\hline Black entrepreneurship vs. job satisfaction & 133 & -0.09 & 0.33 \\
\hline
\end{tabular}


Table 17. Correlation: Fair treatment (White) and career development

\begin{tabular}{llll}
\hline Variable & Count & Spearman & Spearman p-value \\
\hline air treatment vs. career development & 133 & 0.18 & 0.03 \\
\hline
\end{tabular}

Table 18. Correlation: Fair treatment (Black) and career development

\begin{tabular}{llll}
\hline Variable & Count & Spearman & Spearman p-value \\
\hline Fair treatment vs. career development & 77 & 0.35 & $<0.01$ \\
\hline
\end{tabular}

Table 19. Correlation: Job hopping and career development

\begin{tabular}{llll}
\hline Variable & Count & Spearman & Spearman p-value \\
\hline Job hopping vs. career development & 133 & -0.12 & 0.17 \\
\hline
\end{tabular}

Table 20. Correlation: Job hopping (Black) and career development

\begin{tabular}{llll}
\hline Variable & Count & Spearman & Spearman p-value \\
\hline Job hopping vs. career development & 77 & -0.33 & $<0.01$ \\
\hline
\end{tabular}

Table 21. Correlation: Commitment to transformation and career development

\begin{tabular}{lllllll}
\hline Variable & & & Count & Spearman & Spearman p-value \\
\hline $\begin{array}{l}\text { Commitment } \\
\text { development }\end{array}$ & to & transformation & vs. & career & 133 & 0.18 \\
\hline
\end{tabular}

Table 22. Correlation: Corporate culture (Black) and career development

\begin{tabular}{llll}
\hline Variable & Count & Spearman & Spearman p-value \\
\hline Corporate culture vs. career development & 77 & -0.16 & 0.15 \\
\hline
\end{tabular}

Table 23. Correlation: Black entrepreneurship (White) and career development

\begin{tabular}{llll}
\hline Variable & Count & Spearman & Spearman p-value \\
\hline Black entrepreneurship vs. career development & 133 & -0.08 & 0.36 \\
\hline
\end{tabular}

Table 24. Correlation: Fair treatment (White) and tenure in previous job

\begin{tabular}{llll}
\hline Variable & Count & Spearman & Spearman p-value \\
Fair treatment vs. tenure in previous job & 133 & -0.01 & 0.93 \\
\hline
\end{tabular}

Table 25. Correlation: Fair treatment (Black) and tenure in previous job

\begin{tabular}{llll}
\hline Variable & Count & Spearman & Spearman p-value \\
\hline Fair treatment vs. tenure in previous job & 77 & -0.02 & 0.90 \\
\hline
\end{tabular}

Table 26. Correlation: Job hopping (White) and tenure in previous job

\begin{tabular}{llll}
\hline Variable & Count & Spearman & Spearman p-value \\
\hline Job hopping vs. tenure in previous job & 133 & 0.07 & 0.39 \\
\hline
\end{tabular}

Table 27. Correlation: Job hopping (Black) and tenure in previous job

\begin{tabular}{llll}
\hline Variable & Count & Spearman & Spearman p-value \\
\hline Job hopping vs. tenure in previous job & 77 & 0.06 & 0.61 \\
\hline
\end{tabular}


Table 28. Correlation: Commitment to transformation (White) and tenure in previous job

\begin{tabular}{llll}
\hline Variable & Count & Spearman & Spearman p-value \\
\hline $\begin{array}{l}\text { Commitment to transformation } \\
\text { vs. tenure in previous job }\end{array}$ & 133 & 0.07 & 0.40 \\
\hline
\end{tabular}

Table 29. Correlation: Corporate culture (Black) and tenure in previous job

\begin{tabular}{llll}
\hline Variable & Count & Spearman & Spearman p-value \\
\hline $\begin{array}{l}\text { Corporate culture } \\
\text { vs. tenure in previous job }\end{array}$ & 77 & -0.12 & 0.29 \\
\hline
\end{tabular}

Table 30. Correlation: Black entrepreneurship (White) and tenure in previous job

\begin{tabular}{llll}
\hline Variable & Count & Spearman & Spearman p-value \\
\hline $\begin{array}{l}\text { Black entrepreneurship } \\
\text { vs. tenure in previous job }\end{array}$ & 133 & -0.14 & 0.12 \\
\hline
\end{tabular}

Table 31. Correlation: Fair treatment (White) and tenure in current job

\begin{tabular}{llll}
\hline Variable & Count & Spearman & Spearman p-value \\
\hline Fair treatment vs. tenure in current job & 133 & -0.05 & 0.60 \\
\hline
\end{tabular}

Table 32. Correlation: Fair treatment (Black) and tenure in current job

\begin{tabular}{llll}
\hline Variable & Count & Spearman & Spearman p-value \\
\hline Fair treatment vs. tenure in current job & 77 & 0.23 & 0.04 \\
\hline
\end{tabular}

Table 33. Correlation: Job hopping (White) and tenure in current job

\begin{tabular}{llll}
\hline Variable & Count & Spearman & Spearman p-value \\
\hline Job hopping vs. tenure in current job & 133 & 0.09 & 0.30 \\
\hline
\end{tabular}

Table 34. Correlation: Job hopping (Black) and tenure in current job

\begin{tabular}{llll}
\hline Variable & Count & Spearman & Spearman p-value \\
\hline Job hopping vs. tenure in current job & 77 & -0.01 & 0.92 \\
\hline
\end{tabular}

Table 35. Correlation: Commitment to transformation (White) and tenure in current job

\begin{tabular}{llll}
\hline Variable & Count & Spearman & Spearman p-value \\
\hline Commitment to transformation vs. tenure in current job & 133 & -0.20 & 0.02 \\
\hline
\end{tabular}

Table 36. Correlation: Black entrepreneurship (Black) and tenure in current job

\begin{tabular}{llll}
\hline Variable & Count & Spearman & Spearman p-value \\
\hline Black entrepreneurship vs. tenure in current job & 133 & 0.00 & 0.98 \\
\hline
\end{tabular}

Table 37. Correlation: Corporate culture (Black) and tenure in current job

\begin{tabular}{llll}
\hline Variable & Count & Spearman & Spearman p-value \\
\hline Corporate culture vs. tenure in current job & 77 & -0.21 & 0.06 \\
\hline
\end{tabular}

\section{Conclusion}

The study provides statistically significant evidence supporting the link between specific critical success factors and their influence on successful black leadership integration into historically white-dominated JSE-listed companies.

For both black and white managers, job satisfaction is associated with leaders who provide adequate career 
development opportunities, recognition, training, mentoring and fair remuneration. For black managers, job satisfaction also depends on an organisation's commitment to transformation, cultural intelligence, valuing of ethnic diversity and autonomy.

Black managers' reasons for job-hopping include a lack of job satisfaction, placement in "soft jobs" with limited authority (tokenism), insufficient support in dealing with complexity, fear of failure, a lack of trust, open resistance between line and executive management, frustration with corporate culture, exclusion from "inner circles" and language barriers.

The study reveals that for black management, in addition to the provision of adequate career development opportunities, recognition, mentoring, training and remuneration, fair treatment includes organisational commitment to transformation in terms of employment equity and BBBEE, cultural intelligence as well as the valuing of ethnic diversity and autonomy.

The study further revealed that a significant positive statistical relationship exists between job satisfaction/career development and inspirational motivation respectively (inspirational motivation referring to talking optimistically about the future, talking enthusiastically about what needs to be accomplished, articulating a compelling vision of the future and expressing confidence that goals will be achieved) for Black management. However, a significant inverse statistical relationship exists between career development and idealised attributes (instilling pride in others for being associated with me, going beyond self-interest for the good of the group, acting in ways that build others' respect for me and displaying a sense of power and confidence) for Black management exists.

\section{Limitations of the Study}

The following are the limitations of the study:

1. The response rate of senior executives was mere $12 \%$, wherein only 210 out of 1637 executives responded.

2. The lack of larger sample sizes of African, Indian and Coloured race groups might lead to generalisation.

3. No statistical significance was established between Black entrepreneurship as defined by White management and any other independent or dependent variables.

\section{Recommendations to Organisations}

- Effective organisations goes beyond job satisfaction - underpinned by adequate career development opportunities, recognition, mentoring, training and fair remuneration - to increase the tenure of black management. The concept of satisfaction is a mediocrity emotion. Setting a higher emotional target for the employees inspires people. Concepts like raving employees or job excitement can replace the older concept of job satisfaction. Successful organisations design processes to determine the expectations of its talent and take time to meet these expectations in a systemic process.

- Organisations who demonstrate commitment to transformation in terms of employment equity and BBBEE will see a higher retention rate of black management. This commitment can include transformation committees, BBBEE initiatives and close collaboration with black management.

- Organisations should demonstrate that they value ethnic diversity, support community-based organisations and provide autonomy to black managers. This will lead to increased job excitement, retention and career development among black managers as well as other leaders. In some of the most innovative organisations in the world, knowledge creation happens when there are no boundaries in terms of positions. Of course, this requires a solid knowledge creation process in place that extracts the diverse thoughts of leaders and synthesizes them into practical solutions.

- Transformational leaders operate with a greater sense of social responsibility and a spirit of inclusivity, and they believe that managing diversity is not only about legal compliance but rather a moral obligation. Therefore, transformational leadership is critical for South African companies. In many service-based and knowledge-oriented functions, transformational leadership is a foundation for strategic development. While strategies vary, the systemic development of transformational leaders provides a healthy foundation for sustained success.

- To attract and retain black leadership and eliminate job-hopping, organisations should avoid placing black managers in "soft jobs" with limited authority and career advancement opportunities. Organisations should assist black managers to handle increased complexity, resistance between line and executive management, and fear of failure. 
- Organisations should focus on establishing a corporate culture that enhances the job satisfaction of black managers. This means helping to break down "inner circles", isolation and language barriers. While culture is an invisible challenge to organisations, simple actions like the enhancement of organisational policies and processes can make an impact. Rather than placing cultural change on the shoulders of a few people, strategic enhancements within the systems of organisations will enable the alignment of individual expectations and organisational processes.

- Organisations should focus on becoming culturally tuned to certain behaviours, qualities, skills, attitudes and values of colleagues to embrace ethnic diversity. The complexity of making systemic changes can be daunting for many leaders. Seeking understanding is the foundation for successful change. A first step is to start with the values exploration process where individual values are collected and synthesised into a shared value statement (Sun, 2006). From this shared values statement, all other actions are more likely to result in the desired outcomes.

- Further research could focus on the role corporate culture in job satisfaction and career development among black managers; black managers' expectations from corporate South Africa in terms of demonstrating their commitment to transformation and the deracialisation of the economy.

- Organisations should focus on understanding the leadership style preferences of black managers and not force their own dominant ethnocentric culture. Furthermore, organisations should evaluate the effectiveness of current leadership development programmes in organisations.

- Further research can also investigate the influence of independent variables such as reinforcement theory, organisational productivity, management support and improved organisational performance on the integration of black leadership in companies.

\section{References}

Act, B. B. B. E. E. (2004). Government Gazette Republic of South Africa. Cape Town, 463(25899), 1-10.

Antonakis, J., Avolio, B. J., \& Sivasubramaniam, N. (2003). Context and leadership: An examination of the nine-factor full-range leadership theory using the Multifactor Leadership Questionnaire. The Leadership Quarterly, 14(3), 261-295. https://doi.org/10.1016/S1048-9843(03)00030-4

Appelbaum, S. H., \& Valero, M. (2007). The crucial first three months: An analysis of leadership transition traps and successes. Journal of American Academy of Business, 11(1), 1-8.

Bass, B. M., \& Avolio, B. J. (1994). Manual for the team multifactor leadership questionnaire. Mind Garden, Redwood City.

Booysen, L. (2006). Social identity changes: Challenges facing leadership. Diversity in Africa: The Coming of Age of A Continent, 127-156.

Booysen, L. (2007). Barriers to employment equity implementation and retention of blacks in management in South Africa. South African Journal of Labour Relations, 31(1), 47-71.

Brown, J. D. (2009). Statistics Corner Questions and answers about language testing statistics: Principal components analysis and exploratory factor analysis-Definitions, differences, and choices.

Brun, J. P., \& Dugas, N. (2008). An analysis of employee recognition: Perspectives on human resources practices. The International Journal of Human Resource Management, 19(4), 716-730. https://doi.org/10.1080/09585190801953723

Brun, J.P., Biron, C., Martel, J. \& Ivers, H. (2003). Evaluation of workplace mental health: an analysis of human resources management practices. Chair in Corporate Occupational Health and Safety Management at Université Laval, Québec, Canada.

Buys, M. A., Olckers, C., \& Schaap, P. (2007). The construct validity of the revised job diagnostic survey. South African journal of business management, 38(2), 33-40.

Costello, A. B. \& Osborne, J. W. (2005). Best practices in exploratory factor analysis: Four recommendations for getting the most from your analysis. Practical Assessment, Research, \& Evaluation, 10, 1-9.

Creswell, J. W. (2001). Research Design: qualitative, quantitative, and mixed methods. Thousand Oaks. Sage Publications, Inc.

Creswell, J. W. (2006). Qualitative inquiry and research design: Choosing among five traditions (2nd ed.). Sage Publications, Inc. 
Cruz, C. (2006). What drives black talent in South Africa? Management today, 22(6), 24-25.

Defusco, R., McLeavey, D., Pinto, J., \& Runkle, D. (2012). Ethical and Professional Standards and Quantitative Methods. Wiley. NY: USA

Department of Trade and Industry (2004). Phase 1 Code 000 BBBEE "Principles and Definitions of BBBEE", Paras 41-55. Retrieved 22nd January 2011 from http:// www.dti.gov.za

Department of Trade and Industry. (2007). Broad-based black economic empowerment codes of good practice. Government Gazette, (29617).

Dreachslin, J. L., \& Hobby, F. (2008). Racial and ethnic disparities: why diversity leadership matters. Journal of Healthcare Management, 53(1), 8-13.

Dzivhani, I. M. (2016). The relationship between authentic leadership and ethnic identity in South Africa: Ethnic and Gender differences.

Elenkov, D. S., Judge, W., \& Wright, P. (2005). Strategic leadership and executive innovation influence: An international multi-cluster comparative study. Strategic Management Journal, 26(7), 665-682. https://doi.org/10.1002/smj.469

Elliott, J. R., \& Smith, R. A. (2004). Race, gender, and workplace power. American Sociological Review, 69(3), $365-386$

Employment Equity Report. (2011). 11th Commission of Employment Equity Report. Pretoria: Republic of South Africa: Department of Labour.

Employment Equity Report. (2017). 17th Commission of Employment Equity Report. Pretoria: Republic of South Africa: Department of Labour.

Fernandez, L., \& Alsaeed, N. H. Q. (2014). African Americans and Workplace Discrimination. European Journal of English Language and Literature Studies, 2(2), 56-76.

George, D., \& Mallery, M. (2003). Using SPSS for Windows step by step: A simple guide and reference.

George, D., \& Yancey, G. (2004). Taking stock of America's attitudes on cultural diversity: An analysis of public deliberation on multiculturalism, assimilation and intermarriage. Journal of Comparative Family Studies, $1-19$.

Hammer, J. (2015). Finding the facts: South Africa's future leaders. Roggebai, Cape Town: Jack Hammer Executive Report.

Hargis, M. B., Watt, J. D., \& Piotrowski, C. (2011). Developing leaders: Examining the role of transactional and transformational leadership across business contexts. Organization Development Journal, 29(3), 51.

Hood, J. N. (2003). The relationship of leadership style and CEO values to ethical practices in organizations. Journal of Business Ethics, 43(4), 263-273.

Horwitz, F. M., \& Jain, H. (2011). An assessment of employment equity and broad based black economic empowerment developments in South Africa. Equality, Diversity and Inclusion: An International Journal, 30(4), 297-317. https://doi.org/10.1108/02610151111135750

Horwitz, F.M., Jain, H. and Mbabane, L. (2005). Trade union consultation by employers under employment equity legislation. South African Journal of Labour Relations, 29, 4-31.

Hunter, M. L., \& Dantzker, R. D. (2011). Research Methods for Criminology and Criminal Justice: A Primer, Butterworth-Heinemann, USA.

Ivanova, N. L. (2005). Social identity under various sociocultural conditions. Russian Education \& Society, 47(11), 71-87.

Jack, V., Wu, C., Makhari, S., \& Lorio, P. (2004). Pioneers, Powers and Pundits: Influential and Powerful Black Directors. EmpowerDex. Retrieved $2^{\text {nd }}$ February 2011 from http://www.empowerdex.com.

Khanyile, N. \& Maponga, R. (2006). The Rolling Stones. Johannesburg: TNS Research Surveys.

Korostelina, C. (2003). The multi-ethnic state-building dilemma: national and ethnic minorities' identities in the Crimea. National Identities, 5(2), 141-159.

Leonard, A., \& Grobler, A. F. (2006). Exploring challenges to transformational leadership communication about employment equity: Managing organizational change in South Africa. Journal of Communication Management, 10(4), 390-406. 
Lind, D., Marchall, W. \& Wathen, S. (2011). Statistical techniques in business and economics. Boston:

Malanchuk, O. (2005). Social identification versus regionalism in contemporary Ukraine. Nationalities Papers, $33(3), 345-368$.

Maxcy, S. J. (2003). Pragmatic threads in mixed methods research in the social sciences: The search for multiple modes of inquiry and the end of the philosophy of formalism. Handbook of Mixed Methods in Social and Behavioral Research, 51-89.

McCuddy, M. K., \& Cavin, M. C. (2009). The demographic context of servant leadership. Journal of the Academy of Business and Economics, 9(2), 129-139.

McGraw-Hill Irwin.

Meadows, K. A. (2003). So you want to do research? 4: An introduction to quantitative methods. British Journal of Community Nursing, 8(11), 519-526.

Ng, E. S. W., \& Sears, G. J. (2012). CEO leadership styles and the implementation of organizational diversity practices: Moderating effects of social values and age. Journal of Business Ethics, 105(1), 41-52. https://doi.org/10.1007/s10551-011-0933-7

Nishii, L. H., \& Mayer, D. M. (2009). Do inclusive leaders help to reduce turnover in diverse groups? The moderating role of leader-member exchange in the diversity to turnover relationship. Journal of Applied Psychology, 94(6), 1412-1426.

Nzukuma, K. C., \& Bussin, M. (2011). Job-hopping amongst African Black senior management in South Africa: original research. SA Journal of Human Resource Management, 9(1), 1-12. https://doi.org/10.4102/sajhrm.v9i1.360

Osode, P. (2004). The new Broad-based Black Economic Empowerment Act: A Critical Evaluation. Speculum Juris, 107.

Ospina, S., \& Foldy, E. (2009). A critical review of race and ethnicity in the leadership literature: Surfacing context, power and the collective dimensions of leadership. The Leadership Quarterly, 20(6), 876-896. https://doi.org/10.1016/j.leaqua.2009.09.005

Ouseley, H. (2006). Not a numbers game. People Management, 7.

Pallant, J. (2007). SPSS survival manual (3rd ed.). McGrath Hill.

Patrick, A, H. (2011). Knowledge Workers Demography and Workplace Diversity. Journal of Marketing \& Management, 2(2). 38-73.

Payne, S. C., \& Huffman, A. H. (2005). A longitudinal examination of the influence of mentoring on organizational commitment and turnover. Academy of Management Journal, 48(1), 158-168. https://doi.org/10.5465/AMJ.2005.15993166

Peterson, B. (2004). Cultural intelligence: A guide to working with people from other cultures. Yarmouth, ME: Intercultural Press.

Pranaya, D. (2014). Job Hopping-An Analytical Review. International Journal of Research in Business Management, 2(4). 67-72.

Price, A. (2007). Human resource management in a business context. Cengage Learning EMEA.

Rautenbach, F. (2005). Indirect BEE through the JSE. Is South Africa making progress.

Rentilla, C. (2006). Me, myself and I. Entrepreneur, 34 (12), 102-103.

Russette, J. W., Scully, R. E., \& Preziosi, R. (2008). Leadership across cultures: A comparative study. Academy of Strategic Management Journal, 7, 47-61.

Selome, G. J. (2010). The relationship between diversity climate perceptions and turnover intentions (Doctoral dissertation).

Shaw, R. B., \& Chayes, M. M. (2011). Moving Up: Ten questions for leaders in transition (Part II). Leader to Leader, 2011(60), 46-53. https://doi.org/10.1002/1tl.468

Sozbilir, F., \& Yesil, S. (2016). The impact of Cultural Intelligence (CQ) on Cross-Cultural Job Satisfaction (CCJS) and International Related Performance (IRP). Journal of Human Sciences, 13(1), 2277-2294. 
Sun, T. (2006). Leading Sustainable Change through Self-Discovery. In United Nations Global Forum: "Business as an Agent of World Benefit: Management Knowledge Leading Positive Change.

Sun, T. (2009). Mixed Methods Research: Strengths of two methods combined. SMC University, 1-40.

Tangri, R., \& Southall, R. (2008). The politics of black economic empowerment in South Africa. Journal of Southern African Studies, 34(3), 699-716.

Tanski-Mod, R. (2011). Research Thesis-Problems with Retention? An Exploratory Study of African and White Managers and Professionals within the ICT Industry in South Africa (Doctoral dissertation, University of Cape Town).

Tejeda, M. J., Scandura, T. A., \& Pillai, R. (2001). The MLQ revisited: Psychometric properties and recommendations. The Leadership Quarterly, 12(1), 31-52.

Terre Blanche, M., Durrheim, K., \& Painter, D. (2007). Research in practice (4th ed.). Cape Town: University of Cape Town Press.

Vasilaki, A. (2011). The relationship between transformational leadership and postacquisition performance.

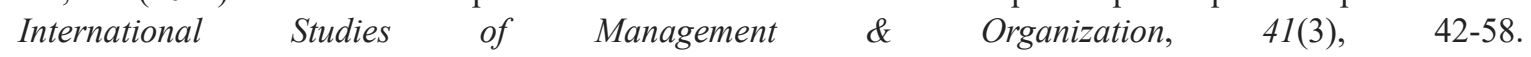
https://doi.org/10.2753/IMO0020-8825410303

Vass, J. (2010). Are black professionals different?: Deconstructing the stereotype.

Zakaria, N., Abdul-Talib, A., \& Osman, N. (2016). Handbook of Research on Impacts of International Business and Political Affairs on the Global Economy. Hershey, PA: IGI Global.

\section{Copyrights}

Copyright for this article is retained by the author(s), with first publication rights granted to the journal.

This is an open-access article distributed under the terms and conditions of the Creative Commons Attribution license (http://creativecommons.org/licenses/by/4.0/). 